ago and their relevance today is limited, given the overall reduction in length of hospital stay, the use of day case surgery, and the introduction of minimally invasive surgery. More recent studies have suggested that hospital at home is a safe and acceptable way of delivering care to patients after repair of a fractured femur ${ }^{3561112}$ or hysterectomy. ${ }^{1314}$ Another recent study, comparing patients with access to hospital at home to those with no access to the service, reported that hospital at home can be cheaper per bed day than hospital care for patients with a fractured femur. ${ }^{4}$ However, these studies were non-randomised and therefore prone to selection bias. One recent randomised study of elderly patients was limited by its small size. ${ }^{7}$ Three randomised trials of hospital at home are currently under way in Britain (UK Collaborative Group on Research and Development of Hospital at Home, North

1 Goldberg AI, Faure E. Home care for life supported persons in England. Chest 1984:86:910-4. 2 Mughal M, Irving M. Home parenteral nutrition in the United Kingdom and Ireland. Lancet 1986;Aug 16:383-7.

O'Caithain A. Evaluation of a hospital at home scheme for the early discharge of patients with fractured neck of femur. $f$ Public Health Med 1995;16:205-10.

4 Hollingsworth W, Todd C, Parker M, Roberts JA, Williams R. Cost analysis of early discharge after hip fracture. $B M \mathcal{F}$ 1993;307:903-6.

Pryor GA, Williams DR. Rehabilitation after hip fractures. Home and hospital management compared. I Bone foint Surg 1989;71B:471-4.

Goldthorpe P, Hodgson E, Evans E, Bradley JG. How we set up an audit of hospital at home in orthopaedic surgery. Medical Audit News 1994;4:40-3

7 Donald IP, Baldwin RN, Bannerjee M. Gloucester hospital at home: a randomized controlled trial. Age Ageing 1995;24:434-9.

8 Marks L Home and hospital care: redrawing the boundaries. London: King's Fund Institure, 1991
Thames Regional Health Authority), ${ }^{15}$ and the first results should be available in 1997 . Until the results of these, and other, studies are available, it will be unclear whether hospital at home schemes represent a new, cost effective direction for health service provision or are merely a substitute technology of limited value and lifespan.

SASHA SHEPPERD Research officer

Health Services Research Unit,

Department of Public Health and Primary Care,

University of Oxford,

Oxford OX2 6HE

STEVE ILIFFE

Reader in primary care

University College London Medical School,

London N19 5NF

Gerson LW, Collins JF A randomized controlled trial of home care: clinical outcome for five surgical procedures. Can $\mathcal{F}$ Surg 1976;19:519-23.

10 Adler MW, Waller JJ, Ca S A. Thorne SC Randomised controlled trial of early discharge for inguinal hernia and varicose veins. 9 Epidemiol Community Health 1978;32:136-42.

11 Farnworth MG, Keeney P, Shiell A. The costs and effects of early discharge in the managemen of fractured hip. Age Ageing 1994;23:190-4.

12 Sikorski JM, Senior J. The domiciliary rehabilitation and support program: rationale, organisation and outcome. Med $\mathcal{F}$ Aust 1993;159:23-5.

13 Hackman B, Navaneethan N. Early discharge after gynaecological surgery. Eur 7 Obstet Gynaecol Reprod Biol 1993;52:57-61.

14 Hancock KW, Scott JS. Early discharge following vaginal hysterectomy. Br $\mathcal{f}$ Obstet Gynaecol 1993;100:262-4.

15 Wisely J, Haines A. Commissioning a national programme of research and development on the interface between primary and secondary care. $B M \mathcal{F}$ 1995;311:1080-2.

\title{
Health and human rights
}

\section{Protecting human rights is essential for promoting health}

When the World Health Organisation redefined health as "a state of complete physical, mental and social well-being" it not only expanded health far beyond medicine, it openly acknowledged the vast accumulated knowledge about the central role of societal determinants of population health. Despite the public's belief to the contrary, medical care is a relatively minor, albeit important, contributor to health, ${ }^{2}$ far outweighed by societal factors, of which social class has been the most extensively studied. ${ }^{34}$

In 1988, a seminal report by the United States Institute of Medicine defined the mission of public health as "ensuring the conditions in which people can be healthy." In turn, this required those working in public health to consider the societal nature of these essential conditions in which people could achieve the highest attainable standard of physical, mental, and social wellbeing. Paradoxically, the discipline of public health has generally ignored the societal roots of health in favour of medical interventions, which operate further downstream. For example, public health efforts at preventing and controlling sexually transmitted diseases have focused on diagnosis and treatment, along with educational programmes, rather than confronting societal inequality or other societal issues as "essential conditions" underlying the spread of sexually transmitted diseases. Epidemiological research has contributed to this narrowed focus, ${ }^{5}$ because it identifies individual risk behaviours in isolation from the critical societal context.

Public health's difficulty in addressing the indisputably predominant societal determinants of health status is exacerbated by the lack of a coherent conceptual framework for analysing societal factors that are relevant to health; the social class approach, while useful, is clearly insufficient. ${ }^{2}{ }^{36}$ Public health action based on social class is often simply accusatory, and it raises, but cannot answer, the question: "what must be done?"
In this sense, "poverty" as a root cause of ill health is both evident and paralysing to further thought and action. Also, without a consistent approach or vocabulary, we cannot identify the societal factors common to different health problems (cancer, heart disease, injuries, infectious diseases) and to different countries. Finally, since the way in which a problem is defined determines what is done about it, the prevailing public health paradigm is unclear about the direction and nature of societal change that is needed to promote public health.

Modern human rights, born in the aftermath of the second world war and crystallised in the Universal Declaration of Human Rights of 1948, reflect a broader, societal approach to the complex problem of human wellbeing. The implicit question behind the modern human rights movement is: "what are the societal (and particularly governmental) roles and responsibilities to help promote individual and collective wellbeing?" This form.of the question leads to a specific list of actions that governments should not do (discriminate, torture, imprison under inhumane conditions, interfere with the free flow of information, invade privacy, prevent associative life in society), and a basic minimum that governments should ensure for all (elementary education, housing, food, medical care). While the word health is mentioned only once in the document, to a public health professional the declaration is about the societal preconditions for "physical, mental and social well-being."

The current health and human rights movement is based on a working hypothesis: that the human rights framework provides a more useful approach for analysing and responding to modern public health challenges than any framework thus far available within the biomedical tradition. The discussion is complicated by the fact that health professionals are generally unaware of the key concepts, meaning, and content of modern human rights. Yet awareness is increasing. Health professionals 
are learning that promoting and protecting human rights may be essential for promoting and protecting health. This insight was already present in the evolving approach to population and women's health. ${ }^{78}$ It was strongly accelerated in work on HIV and AIDS, in which discrimination (and other human rights issues) were found not only to be tragic results of the pandemic but to be root societal causes of vulnerability to HIV. ${ }^{9}{ }^{10}$ Even the World Bank, not generally involved with human rights agendas, reached a similar conclusion when it declared that ensuring girls' rights to education and to non-discrimination within education represented one of the most powerful strategies for improving health in the developing world. ${ }^{11}$

The world of health and human rights has moved away from earlier simplistic assumptions about a necessary conflict between public health goals and human rights norms. ${ }^{12}$ Public health professionals increasingly recognise that they must deal directly with the underlying societal issues that determine, to the largest extent, who lives and who dies, when, and of what. For this reason, since 1990, all graduates of the Harvard School of Public Health receive, along with their diploma, a copy of the Universal Declaration of Human Rights. The dean tells them that this will be as important to their future work as a Hippocratic oath would be for a practising clinician. Ultimately this approach, linking human rights work with public health, is both a return to the historical concerns of public health and the beginning of a new chapter in the relationship between health and society.

JONATHAN M MANN

François-Xavier Bagnoud professor of health and human rights

Harvard School of Public Health,

Boston, MA 02138,

USA

1 World Health Organisation. Constitution. In: Basic documents. 36th ed. Geneva: WHO, 1986.

2 Evans RG. Introduction. In: Evans RG, Barer ML, Marmor TR, eds. Why are some people healthy and others not? Hawthorne, NY: Aldine De Gruyter, 1994:3-26.

Adler NE, Boyce T, Chesney MA, Cohen S, Folkman SM, Kahn RL, et al. Socioeconomic status and health: the challenge of the gradient. Am Psychol 1994;49:15-24.

4 Institute of Medicine. Future of public health. Washington DC: National Academy Press, 1988:1-7.

5 Krieger N. Epidemiology and the web of causation: has anyone seen the spider? Soc Sci Med 1994;39:887-903.

6 Mann JM, Gostin L, Gruskin S, Brennan T, Lazzarini Z, Fineberg H. Health and human rights. Health and Human Rights 1994;1:6-23.

7 Correa S, Petchesky R. Reproductive and sexual rights: a feminist perspective. In: Sen G, Germain A, Chen L, eds. Population policies reconsidered: health, empowerment and rights. Cambridge, MA: Harvard University Press, 1 994:107-23.

8 Cook RJ. Gender, health and human rights. I. 1995; 1:350-66.

9 Mann JM, Tarantola D, Netter T, eds. AIDS in the world. Cambridge, MA: Harvard University Press, 1992:577-602.

10 Mann JM. AIDS in 1994: the personal and global challenge of renewal. In: Shiokawa Y, Kitamura T, eds. Global challenge of AIDS: ten years of HIVIAIDS research. Tokyo: Kodansha, 1995:291-7.

11 World Bank. World development report 1993: investing in health. New York: Oxford University Press, 1993:1-16.

12 International Federation of Red Cross and Red Crescent Societies. AIDS, health and human rights: an explanatory manual. Geneva: The Societies, 1995.

\title{
Travel associated illness
}

\author{
We need to stop blaming the victim
}

If you develop diarrhoea and vomiting on a foreign holiday this year, who is responsible? Some might argue that, because these symptoms are so common, affecting typically between $30 \%$ and $40 \%$ of people holidaying abroad, no one can be blamed. ${ }^{12}$ Others might argue that it is your own fault, for not taking the advice that is available in many popular books and government leaflets on travellers' health. But what if your illness is part of an outbreak affecting a large number of people staying at the same hotel or travelling on the same plane? Should you still simply accept it or should you hold the airline, the hotel management, the travel agent, or someone else responsible?

In Britain until 1992, legal liability in the event of an outbreak such as this was governed by the general laws of contract and tort, in the same way as it would be if it occurred in England or Wales. Although it was possible to obtain damages for certain categories of loss, ${ }^{3}$ the holidaymaker faced considerable challenges, not least in identifying whom to sue because a package holiday, by definition, often included services from a range of suppliers, some of whom may not be within the jurisdiction of the English court. Thus there was considerable scope for shifting responsibility. This situation changed with the enactment in English law of the European directive on package holidays. ${ }^{4}$ In essence, if the package has been offered for sale in the European Union, regardless of where in the world it actually takes place, and includes any two of travel, accommodation, or other significant services, the tour operator is responsible for anything that goes wrong, irrespective of whether the services at fault were provided by that operator or by someone else. ${ }^{5}$ It is sufficient to show that an outbreak is associated with the package provided. This might be that a group of people staying at the same hotel all developed diarrhoea and vomiting at the same time. The burden of proof then shifts to the operator to show that either the outbreak can be blamed on the holidaymaker or it was caused by a third party who is unconnected with the operator and it was both unavoidable and largely unforeseeable. It will be difficult to mount such a defence unless the operator has undertaken a detailed epidemiological investigation. Some tour operators do administer questionnaires in these circumstances but they may be totally inadequate-for example, asking for food histories only from those affected and not from controls.

The response of the travel industry to diarrhoeal outbreaks has often been inadequate. It is usually regarded as no more than a mild inconvenience, even though it can occasionally lead to hospitalisation or even death. Furthermore, the economic consequences can be considerable. The average cost to the individual and the health service of a case of Salmonella enteritidis infection has been put at about $£ 800$, ${ }^{6}$ but the loss incurred by someone on an expensive holiday could be much greater.

Tourism should involve a partnership between the travel industry, the host country, and the tourist. Protecting the health of the tourist requires that countries wishing to promote themselves as mass tourist destinations invest in their infrastructure. The travel industry needs to ensure that tourists are made aware of the risks of travelling and the steps that they should take to minimise the risk of falling ill. Selling glamour without providing the tourist with information about the health hazards of the destination is dishonest.

Pre-travel health advice given by travel agents is often inadequate. ${ }^{7}$ At resorts, local staff receive little training on the action to be taken in the event of an outbreak, and evidence of recurring outbreaks may be ignored. The threat posed to the travel industry by the European directive should be used to encourage a dialogue with those experienced in travel medicine, so as to get better health advice to the tourist and improve the capacity of the travel industry to respond appropriately. In Britain, liaison is already occurring between the Communicable Diseases Surveillance Centre, the Department of Health, and responsible elements of the travel indus- 